\title{
Congenital Anomalies at Birth: A Hospital Based Study in UAE
}

\author{
Aryasinghe L' ${ }^{1}$, Moezzi $D^{2}$, Ansari TA ${ }^{3}$, Khoury ${ }^{4}$, Mathew $E^{5}$, Sharbatti SA ${ }^{6}$, Shaikh RB ${ }^{7}$ \\ ${ }^{1}$ Dr. Lasanthi Aryasinghe, ${ }^{2}$ Dr. Delaram Moezzi, ${ }^{3}$ Dr. Thana Al Ansari, ${ }^{4}$ Dr. Reem Khoury, ${ }^{5}$ Prof. Elsheba Mathew, ${ }^{6}$ Prof. \\ Shatha Al Sharbatti, ${ }^{7}$ Assistant Prof. Rizwana B Shaikh. All from the Department of Community Medicine, College of \\ Medicine, Gulf Medical University, Ajman, UAE.
}

Address for correspondence: Prof. Elsheba Mathew, E-mail: researchdivision2@gmail.com

\begin{abstract}
Introduction: It is widely acknowledged that congenital anomalies heavily contribute to infant morbidity and mortality worldwide, with an estimated 9 million infants ( $7 \%$ of all births) born annually having a serious congenital anomaly that result in death or lifelong disability. The objective of our study was to estimate the frequency of congenital anomalies at the Gulf Medical College Hospital and Research Center, Ajman and to estimate the proportion of births with congenital anomalies per 1,000 live births. Materials and Methods: It was a Hospital-Record based descriptive study of the 1,222 consecutive live births from December 2007 to June 2008. Results: There were 84 cases of congenital anomalies among the 1,222 live births; the rate of anomalous births was 68.7 per 1,000 live births or $6.9 \%$. Anomalies of the genitourinary system (40.5\%) were the most common, followed by musculoskeletal (28.6\%) and cardiovascular (10.7\%). Gastrointestinal, chromosomal and multiple system anomalies accounted for 3.6\% each and miscellaneous anomalies were seen in $7.1 \%$. Central Nervous system (2.4\%) anomalies were the least. Congenital hydrocele (19.0\%) was seen to have the highest frequency amongst all recorded anomalies, followed by Talipes or Clubfoot (14.3\%). $9.3 \%$ of the male and $4.3 \%$ of the female population of live births had a congenital anomaly. Birth Weight $(p=0.005)$ and Gender $(p=0.001)$ were found to have significant association with the frequency of birth defects. Maternal Age, gravidity, parity, previous abortions, VDRL and Hepatitis B status, Gestational Diabetes, Pregnancy Induced Hypertension, gestational age, maternal and infant blood group, nationality and consanguinity showed no statistically significant association with congenital anomalies. Conclusion: The proportion of congenital anomalies found in our study is alarmingly high and emphasizes the need for more accessible nationwide screening, counseling and surveillance systems.
\end{abstract}

Key words: Congenital anomalies, congenital malformations, risk factors, maternal and infant variables, Hospital-record based, United Arab Emirates

\section{Introduction}

A congenital anomaly is defined as any abnormality present at birth, either structural or functional, which may have been inherited genetically, acquired during gestation, or inflicted during parturition'. The EUROCAT Registry reports that up to $14 \%$ of neonates are born with a single minor malformation, 2-3\% will have a single major malformation, and less than $1 \%$ of neonates have multiple malformations ${ }^{2}$.

Manuscript received: $11^{\text {th }}$ March 2012.

Reviewed: $30^{\text {th }}$ March 2012

Author Corrected: $10^{\text {th }}$ April 2012

Accepted for Publication: $30^{\text {th }}$ April 2012
Malformations may also be divided according to causal factors, with $20-25 \%$ of all abnormalities having a multifactorial etiology and $50-60 \%$ having no identifiable cause (Idiopathic) ${ }^{2}$. Environmental factors (maternal illness, infections, drugs, radiation and alcohol) account for $6-8 \%$ of birth defects, single gene mutations represent a further $6-8 \%$ and $6-8 \%$ result from chromosomal disorders ${ }^{2}$.

It is widely acknowledged that congenital anomalies heavily contribute to infant morbidity and mortality worldwide, with an estimated 9 million infants (7\% of all births) born annually having a serious congenital anomaly that result in death or lifelong disability ${ }^{3}$. 
The United Arab Emirates ranked sixth worldwide for the prevalence of birth defects ${ }^{4}$, and congenital anomalies account for a shocking $86.1 \%$ of all infant deaths in the country per year ${ }^{5}$. The last published data (2001) from the National Congenital Abnormalities Registry notes the rate of congenital anomalies to be about 8.0 per 1,000 live births ${ }^{6}$. This places a substantial financial strain on the government in the form of medical and support services, with the economic impact of just genetic disorders estimated to be as high as $\$ 200$ million per annum? ${ }^{7}$.

The Middle Eastern region has a racially varied population, high percentage of consanguineous marriages and an older reproductive age group; these unique socio-cultural characteristics are particularly significant when it comes to understanding the prevalence, pathogenesis and socioeconomic impact of congenital anomalies ${ }^{8}$.

Past studies conducted within the UAE, while comprehensively quantifying and describing the anomalies themselves, do not co-relate the results with multiple causative factors ${ }^{6}$. It is for this reason that our study took into account the frequency of the various birth defects as well as numerous maternal and infant variables to give us an insight into the important etiologies for this region. With clearer data, it will be possible to both identify and prevent the major risk factors as well as educate the public, equip healthcare professionals and refine existing genetic screening systems.

\section{Materials and Methods}

Study Design: This was a hospital-record based, descriptive study of all the live births during a six month period from December 2007 to June 2008 at the Gulf Medical College Hospital and Research Center, which is the main teaching hospital in Ajman, United Arab Emirates.

There were a total of 1,222 live births, including over 45 different nationalities, 621 male infants, 599 female infants and mothers aged from $16-48$ years.

Congenital anomalies, congenital malformations, and birth defects are all terms used to describe a structural or functional abnormality present at birth, which might be clinically obvious at the time of birth or diagnosed later on in life ${ }^{4}$. However since this is a recordbased study, the anomalies included in the study are only cases that were clinically diagnosed at the time of birth by a pediatrician. Anomalous cases were determined and categorized according to organ system by following the International Classification of Diseases (ICD-10).
In cases where more than one organ system involved was classified as 'Multiple Systems'. Cases of eye, ear, respiratory, and unconfirmed cases of Neural Tube Defects were grouped as 'Others' due to the small number of cases.

Each newborn has a standard 'Birth Detail' form filled by the pediatrician immediately after birth, this form includes several infant and maternal variables, including any delivery complications, birth defects and APGAR scores. We collected our data directly from this form into our MS Excel data collection sheets. All patient data was kept strictly confidential and anonymity of subjects was maintained at all times.

We used Predictive Analytics Software (SPSS Version 17.0) for data analysis. Analyses included frequency distributions, percentages and Chi-Square testing ( $P$ $<0.05)$ for statistical association. Finally we calculated the proportion of anomalous cases to normal births per 1,000 live born using the formula: (Number of live born infants with congenital anomalies x 1,000$) /$ Total no. of live births

\section{Results}

During the six month study period there were 1,222 live births. The following tables and charts demonstrate the various population distributions pertaining to each of our predictor variables.

Table 1 gives the distribution of births based on the maternal factors of age, gravidity, parity and abortions. It is seen that the majority of the mothers are aged between $25-34$ years (61.4\%) with only $1.4 \%$ of the mothers were over the age of 40 years. Almost half $(48.4 \%)$ of our maternal population have had at least 2-3 previous pregnancies with 6.8\% (80) reporting over 6 previous pregnancies, and 329 (27.8\%) being primigravid. As for parity, 711 (60.4\%) of women had 1-3 viable live births in the past, followed by 359 (30.5\%) of women who were nulliparous. However only 22 (1.9\%) of women were grandmultiparous ( $\geq 6$ viable pregnancies). Over three-quarters of the population (80.2\%) reported never having an abortion or miscarriage, $18.5 \%$ had $1-2$, and less than $2.0 \%$ of the population reported having over 3 abortions/miscarriages.

Gender distribution in our population was almost equal with $50.9 \%$ (621) composed of male newborns; the remaining $49.1 \%$ (599) were female, and 1 case of ambiguous genitalia. Gestational age showed 6.6\% (75) pre-term births and a much lower 1.2\% (13) post-term births, majority of births $92.2 \%$ (1041) were full term between $37-41$ weeks of gestation. The percentage of low $(\leq 2.4 \mathrm{~kg})$ and high ( $\geq 4.0 \mathrm{~kg}$ ) birth weights were 
similar at 5.5\% (67) and 5.6\% (68) respectively, and again majority of births $88.9 \%$ (1079) fell in the normal birth weight range $(2.5-3.9 \mathrm{~kg})$. One minute APGAR scores were generally normal $(\geq 7)$ in over $98.8 \%$ (1198) of the population and less than $1.2 \%$ (15) showing scores 6 or less.

This table summarizes the different anomalies according to body system. Among the total 1,222 live births in the six months, there were 84 (6.9\%) infants born with a congenital anomaly; ranging from minor to major, single to multiple systems. Genitourinary malformations formed the bulk of the anomalous population at $40.5 \%$ (34), followed by Musculoskeletal anomalies accounting for $28.6 \%$ (24) of anomalies. Cardiovascular anomalies were third with $10.7 \%$ (9), miscellaneous anomalies such as cases of tongue-tie and choanal atresia accounted for $7.1 \%$ (6) and Central Nervous System anomalies showed the lowest frequency with only $1.6 \%$ (2).

The proportion of births with congenital anomalies per 1,000 live births is 68.7. Genitourinary anomalies show the highest rate of 27.8 cases per 1,000 live births, followed by musculoskeletal anomalies with a rate of 19.6 cases per 1,000 live births. Gastrointestinal, Chromosomal and Multiple System anomalies had an equal rate of 2.5 cases per 1,000 live births.

Among all the anomalies, Congenital Hydrocele $(13 / 1000)$ and Talipes $(9.82 / 1000)$ were the most frequent anomaly, while majority of the other anomalies had a rate of 0.82 per 1,000 live births. Additional findings included several cases of birth injuries; 5 cases $(0.4 \%)$ of Erb's palsy and 1 case of Klumpke's palsy $(0.08 \%)$, as well as $8(1.3 \%)$ twin pregnancies.

Figure 1 is a percentage bar chart showing the distribution of anomalies by organ system amongst the anomalous population. Genitourinary, musculoskeletal and cardiovascular system anomalies were the most common in the descending order.

Table 3 shows the distribution of anomalous births according to the different maternal and infant variables. The distribution amongst the maternal age groups appears almost uniform; in mothers aged between 25 and 34 years, $7.5 \%$ had an infant born with a congenital anomaly which was the highest frequency, followed by the 15 - 24 age group with $6.8 \%$; and this value seems to decrease as age increases, the lowest frequency being seen in women $\geq 35$ years, (6\%). The Chi-Square test was carried out to identify a possible association between maternal age and congenital anomalies but showed no significance. Only 2 mothers had reactive VDRL, of them one gave birth to a baby with no congenital anomaly and the other had a baby with a congenital anomaly. There was 1 case (10\%) of congenital anomaly among the 10 women infected with Hepatitis B.

None of the mothers with pre-existing diabetes gave birth to infants with a birth defect. $6.6 \%$ of non-diabetic women gave birth to an infant with an anomaly, while women with Gestational Diabetes Mellitus (GDM) demonstrated double the incidence (12.1\%); however this was not proved to be statistically significant. Pregnancy Induced Hypertension showed no association with congenital anomaly and in fact a demonstrated lower rate $(4.6 \%)$ of anomalies than the non-hypertensive population (7.0\%).

When examined by gravidity, the frequency of anomalies did not vary significantly; the lowest of anomalies were seen in women who had been pregnant 4-5 times $6.4 \%$ (13) and the highest of 7.5\% (6) in women with gravidity $>6$. Of all the primigravid women $6.7 \%$ (22) had infants born with an anomaly and only $7 \%$ (40) was seen in women with 2-3 previous pregnancies. A history of previous abortions showed no correlation with the rate of anomalies, with the highest frequency of anomalies $8.3 \%$ (18) seen in women with a history of 1-2 previous abortions, but women with $\geq 5$ abortions showed zero incidence of infants with an anomaly. Women with no history of previous abortion or miscarriage had the lowest frequency of $6.6 \%$ (62) of anomalies.

Male infants showed a frequency of congenital anomalies at $9.3 \%$ (58) which is over twice as much seen in female infants, which was $4.3 \%$ (26). This is a important finding as our study population comprised of equal proportions of male and female infants; Chisquare testing also showed a very strong statistical significance $(P=0.001)$. Preterm infants showed the highest frequency of $8.0 \%$ (6) anomaly, whereas only $6.7 \%(70)$ infants born after 37 weeks had a congenital anomaly, gestational age was however not statistically significant. Both low and high weight classes clearly exhibit higher frequencies of anomalies with 9.0\% (6) and $16.2 \%$ (11) respectively, with infants born with a weight $>4.0 \mathrm{~kg}$ showing the highest frequency. Infants of the normal weight class showed a lower frequency of $6.1 \%$ (66), birth weight was found to also be a statistically significant variable $(\mathrm{P}=0.005)$.

The highest frequency of infants with congenital anomalies is seen in mothers and infants with Blood Group A with $8.8 \%$ and $7.6 \%$ respectively. The lowest rate was seen in mother's blood group $B$ with only $4.8 \%$, Type $O$ and $A B$ with 30 (6.5\%) and 7 (7.9\%) respectively. Infant blood group $A B$ had the lowest proportion of anomalies, 3.8\%; Type A: 7.6\%, Type B: 7.1\% and Type 
O: $6.2 \%$. Neither maternal nor infant blood groups were found to be statistically significant.

Our study had only three cases of consanguinity, of which one showed a congenital anomaly. 83 (6.8\%) nonconsanguineous couples had an infant with a congenital anomaly and this percentage was almost five-fold less than in consanguineous couples, $33.3 \%$ (1).

Distribution of anomalies by the socio- demographic variable of nationality showed that Europeans who constituted only $1.8 \%$ (22) of our study population, had the highest frequency of anomalies at $18.2 \%$ (4). However our largest population from the Indian subcontinent which formed $52 \%$ (630) of the study group showed a rate of only $7.8 \%$ (49) followed by our second largest population from the Middle East with $6.3 \%$ (25). Africans showed the lowest frequency of $2.4 \%$ (3) and only $3.4 \%$ (1) of subjects from the Far East had an infant with a congenital anomaly.

Table 1: Distribution of maternal variables: Age, gravidity, Parity and Abortions

\begin{tabular}{|c|c|c|}
\hline Maternal Variables & Frequency & Percent (\%) \\
\hline \multicolumn{3}{|l|}{ Maternal Age } \\
\hline $15-24$ yrs & 310 & 27.0 \\
\hline $25-34$ yrs & 705 & 61.4 \\
\hline $35-39 y r s$ & 117 & 10.2 \\
\hline$\geq 40 \mathrm{yrs}$ & 16 & 1.4 \\
\hline Total & 1148 & 100.0 \\
\hline \multicolumn{3}{|l|}{ Gravidity } \\
\hline Primigravid (1) & 329 & 27.8 \\
\hline $2-3$ & 573 & 48.4 \\
\hline $4-5$ & 202 & 17.1 \\
\hline$\geq 6$ & 80 & 6.8 \\
\hline Total & 1184 & 100.0 \\
\hline \multicolumn{3}{|l|}{ Parity } \\
\hline Nulliparous (0) & 359 & 30.5 \\
\hline $1-3$ & 711 & 60.4 \\
\hline $4-5$ & 86 & 7.3 \\
\hline$\geq 6$ & 22 & 1.9 \\
\hline Total & 1178 & 100.0 \\
\hline \multicolumn{3}{|l|}{ Abortions } \\
\hline 0 & 945 & 80.2 \\
\hline $1-2$ & 218 & 18.5 \\
\hline $3-4$ & 14 & 1.2 \\
\hline$\geq 5$ & 2 & 0.2 \\
\hline Total & 1179 & 100.0 \\
\hline
\end{tabular}

Table 2: Total no. and prevalence rates of congenital anomalies by organ system Dec 2007-June 2008

\begin{tabular}{|l|c|c|}
\hline \multicolumn{1}{|c|}{ System } & Frequency & Rate Per 1,000 Live Births \\
\hline Genitourinary & 34 & 27.8 \\
\hline Musculoskeletal & 24 & 19.6 \\
\hline Cardiovascular & 9 & 7.4 \\
\hline Others & 6 & 4.9 \\
\hline Gastrointestinal & 3 & 2.5 \\
\hline Chromosomal & 3 & 2.5 \\
\hline Multiple Systems & 3 & 2.5 \\
\hline Central Nervous System & 2 & 1.6 \\
\hline \multicolumn{1}{|c|}{ Total } & $\mathbf{8 4}$ & $\mathbf{6 8 . 7}$ \\
\hline
\end{tabular}


Table 3: Congenital anomalies by maternal and infant factors

\begin{tabular}{|c|c|c|c|c|c|c|c|}
\hline \multirow{3}{*}{ Variables } & \multirow{3}{*}{ Group } & \multicolumn{6}{|c|}{ Congenital Anomaly } \\
\hline & & \multicolumn{2}{|c|}{ Yes } & \multicolumn{2}{|c|}{ No } & \multicolumn{2}{|c|}{ Total } \\
\hline & & No. & $\%$ & No. & $\%$ & No. & $\%$ \\
\hline \multirow{3}{*}{ Maternal Age } & $15-24$ years & 21 & 6.8 & 289 & 93.2 & 310 & 100 \\
\hline & 25 - 34 years & 53 & 7.5 & 652 & 92.5 & 705 & 100 \\
\hline & $\geq 35$ years & 8 & 6.0 & 125 & 94.0 & 133 & 100 \\
\hline \multirow{2}{*}{ Maternal VDRL } & Negative & 83 & 6.8 & 1137 & 93.2 & 1220 & 100 \\
\hline & Reactive & 1 & 50.0 & 1 & 50.0 & 2 & 100 \\
\hline \multirow{2}{*}{ Maternal Hbv } & Negative & 83 & 6.8 & 1129 & 93.2 & 1212 & 100 \\
\hline & Positive & 1 & 10.0 & 9 & 90.0 & 10 & 100 \\
\hline \multirow{2}{*}{$\begin{array}{l}\text { Gestational } \\
\text { Diabetes }\end{array}$} & Absent & 76 & 6.6 & 1077 & 93.4 & 1153 & 100 \\
\hline & Present & 8 & 12.1 & 58 & 87.9 & 66 & 100 \\
\hline \multirow{2}{*}{ Gestational Age } & Preterm < 36 weeks & 6 & 8.0 & 69 & 92.0 & 75 & 100 \\
\hline & $\geq 37$ weeks & 70 & 6.6 & 984 & 93.4 & 1054 & 100 \\
\hline \multirow{2}{*}{ Gender } & Male & 58 & $9.3 \%$ & 563 & 90.7 & 621 & 100 \\
\hline & Female & 26 & $4.3 \%$ & 573 & 95.7 & 599 & 100 \\
\hline \multirow{3}{*}{ Birth Weight } & $\operatorname{Low}(\leq 2.4 \mathrm{~kg})$ & 6 & 9.0 & 61 & 91.0 & 67 & 100 \\
\hline & Normal $(2.5$ - 3.9kg) & 66 & 6.1 & 1013 & 93.9 & 1079 & 100 \\
\hline & $\operatorname{High}(\geq 4.0 \mathrm{~kg})$ & 11 & 16.2 & 57 & 83.8 & 68 & 100 \\
\hline
\end{tabular}

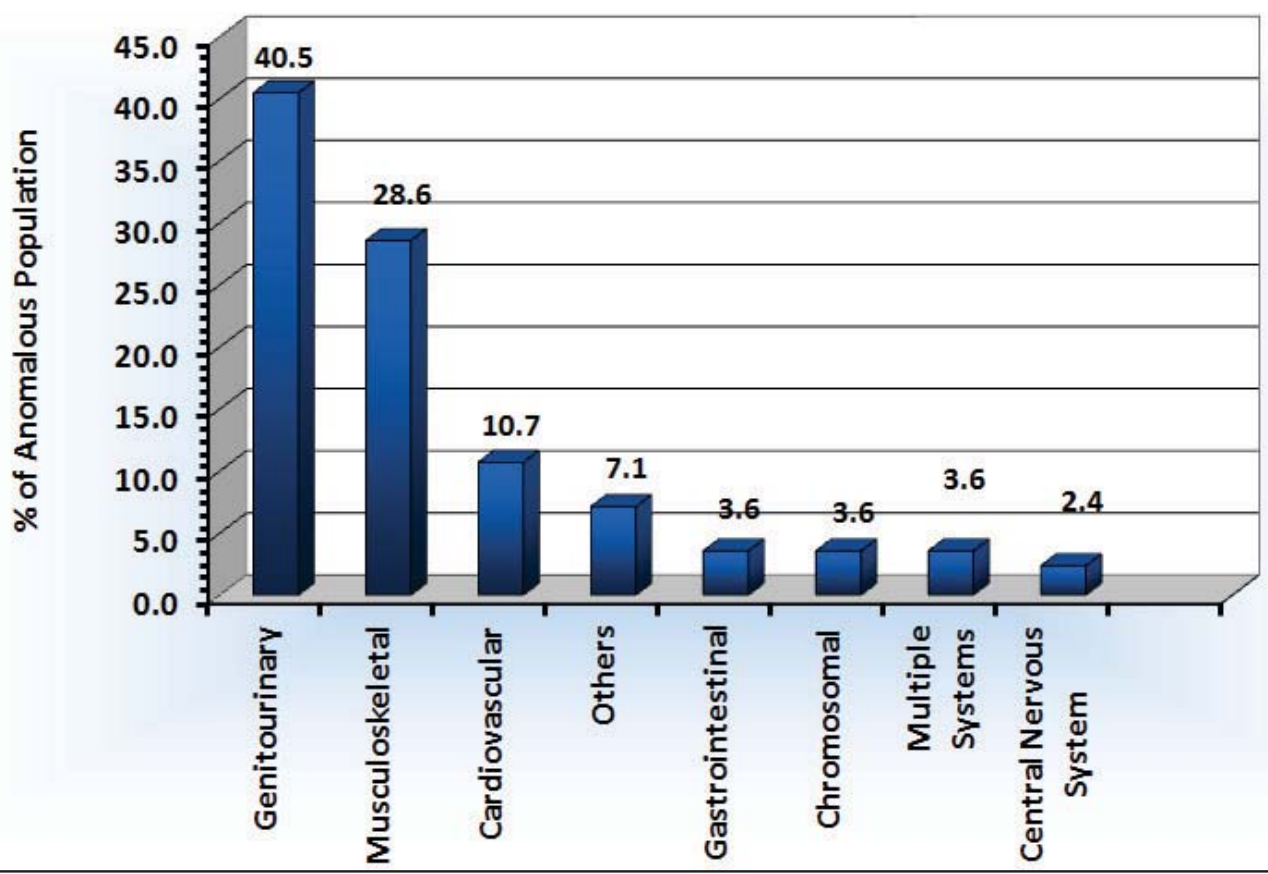

Fig 1: Congenital anomalies by organ system and percentage of Anomalous Population

\section{Discussion}

Our study has been a comprehensive examination of not only the frequency of congenital anomalies among all the live births in the six month study period, but also a thorough assessment of several maternal and fetal variables. The main objectives were to estimate the proportion of anomalous births per 1000 live births and to identify any association between the outcome and predictor variables.
Since the only information available to us was live births we calculated the Rate of anomalies per 1000 live born; ideally the total rate of congenital anomalies is calculated per 1000 births, however this definition takes into account all births (live \& still born), fetal deaths from 24 weeks gestation and induced abortions or terminations of pregnancy after prenatal diagnosis. There were 84 cases of single or multiple congenital anomalies among the 1,222 live births that occurred 
during Dec 2007 - June 2008. The proportion or rate was therefore 68.7 cases per 1000 live births or $6.9 \%$.

The March of Dimes Global Report on Birth Defects (2006) reports rates in the UAE to be $75.9 / 1000$ live births ${ }^{4}$, which lends credibility to our study due to the similarity in our rate. However the National Congenital Anomalies Register (1999-2001) in the UAE reports a remarkably lower rate of $8.0 / 1000$ live births ${ }^{6}$ and the reason for this is because the registry excludes minor anomalies that do not require medical intervention such as congenital hydrocele, whereas our rate accounts for both minor and major congenital anomalies.

March of Dimes also estimates the rate of birth defects to be $>69.9 / 1000$ live births in most Arab countries, compared to rates of $<52.0 / 1000$ live births in North America, Europe, China and Australia4. However contrary to the rates reported by March of Dimes, studies in the Gulf region report significantly lower rates: Saudi Arabia 27.06/1000 livebirths ${ }^{9}$, Iran 27.19/1000 livebirths ${ }^{10}$, Bahrain 24.47/1000 live births ${ }^{11}$.

A possible explanation for the very high rate of Genitourinary (27.8/1000) and Musculoskeletal anomalies (19.6/1000) in our study, is that they are more obvious at birth than other types of anomalies and are therefore more commonly recorded. Studies done in the UAE in the past report cardiovascular system anomalies as the most common followed by chromosomal $(0.8 / 1000)$ and then musculoskeletal ${ }^{6}$. Congenital hydrocele $(13.09 / 1000)$ and undescended testis (7.36/1000) accounted for the majority of the genitourinary cases. The most frequent anomaly in the musculoskeletal system was Talipes (Clubfoot) (9.82/1000), there was also 1 case of Lobster-Claw Syndrome and 1 case of Oligodactyly (foot) recorded. The rate of Talipes in our study is substantially higher than those reported in countries like Iran $(3.95 / 1000)^{10}$ and the UK $(1.0 / 1000)^{12}$. Urogenital anomalies only accounted for $1.2 / 1000$ in the UK $^{12}$. Developmental Dysplasia of the Hip had a rate of $8.8 / 1000$ in this study which is much higher than the rate reported in the UK (1.5/1000); however 6.0/1000 is the rate at initial diagnosis even in the UK, which is more comparable to our results, as most newborns demonstrate an abnormal initial clinical examination ${ }^{12}$.

The rate of congenital heart defects in our study was 7.4/1000 and this falls within the ranges reported by countries such as Saudi Arabia (7.1/1000) ${ }^{9}$ and the UK (6$8 / 1000)^{12}$. Gastrointestinal anomalies accounted for 3.6\% $(2.5 / 1000)$ of defects, with our rate of cleft palate being $0.82 / 1000$, which is equal to the rate reported by in the UK ${ }^{12}$.

In our research, chromosomal aberrations accounted for $3.6 \%$ of birth defects $(2.5 / 1000)$ which is comparable to the rate of $3.1 / 1000$ that was reported by a study carried out on 24,233 hospital births in Abu Dhabi $^{13}$. The rate of Down's syndrome in our study was $1.64 / 1000$ which is less than the rate of $2.2 / 1000$ reported in a study done on 63,398 newborn babies in Dubai ${ }^{14}$. However this rate is close to the rate of $1.2 / 1000$ that is expected to be seen in a high-income country versus rates of $2-3 / 1000$ in low to middle income countries ${ }^{3}$.

Based on established data an increasing maternal age is conducive to the incidence of congenital anomalies, however on testing this association with our data there was no statistically significant association seen. However $9.7 \%$ of the anomalous population had associated maternal age $\geq 35$ years and musculoskeletal and genitourinary anomalies were the most common types of anomalies in infants with older mothers, followed by cardiovascular anomalies. We attribute the lack of significant association in our study due to the extremely small population of women over 35 years (11.6\%) with majority being less than 34 years (88.4\%). Even though our data showed a steady increase in the frequency of anomalies in women with higher parity, the association was not significant. In contrast to our findings, both advanced maternal age and increasing parity have been implicated in other studies with higher occurrences of birth defects, and this is especially significant in the Arab region where women continue child-bearing until menopause ${ }^{6,8,15}$. A Case-Control study in Saudi Arabia of 30,159 live born infants, found mothers of neonates with chromosomal malformations, were older and of greater parity than control groups ${ }^{15}$.

It was found that $8.8 \%$ of mothers with Blood Group A gave birth to an infant with an anomaly this being the highest frequency among the maternal $A B O$ phenotypes, followed by Group AB with 7.9\%, Group O with $6.5 \%$ and Group B having the lowest with $4.8 \%$. Similar to maternal blood type, infants with Group A are seen to have the highest frequency of anomalies with $7.6 \%$, only $3.8 \%$ of infants with blood group $A B$ were found to have anomalies. Type $B$ which was seen to have lowest frequency amongst maternal groups was the second highest among infant blood types, with $7.1 \%$. Congenital anomalies among infants with Group $\mathrm{O}$ was $6.2 \%$, which is similar to the maternal rate of $6.5 \%$ for the same blood group; however a statistically significant association was not found. A review of literature revealed only one comprehensive study of 14,018 births carried out in 1963 to study maternal blood group and pregnancy complications; however it too failed to demonstrate a significant association between maternal blood group and congenital anomalies ${ }^{16}$. Other studies done to relate patient $A B O$ type to congenital cardiac defects $^{17}$, and central nervous system anomalies and 
maternal $\mathrm{ABO}^{18}$ type also failed to reveal any statistical correlation.

Our results for maternal VDRL status are inconclusive due to the fact that only 2 mothers $(0.16 \%)$ in our study population had a reactive VDRL. However many other studies have shown that maternal syphilis may lead to several adverse pregnancy outcomes such as abortions, still births, Intra-uterine growth restriction and congenital anomalies ${ }^{19}$. Of the 10 mothers that tested positive for Hepatitis B, only 1 (10\%) gave birth to an infant with an anomaly, however this was not seen to be statistically relevant. Studies have shown that maternal HBV status does not increase the risk of congenital anomalies, and the sequelae of perinatal hepatitis B infection is usually not symptomatic in the neonatal period ${ }^{19}$.

Among those neonates with a congenital anomaly, 9.5\% had mothers with Gestational Diabetes Mellitus, and mothers with GDM showed a higher frequency $(12.1 \%)$ of having a child with an anomaly as compared to a non-diabetic mother (6.6\%), and although the figure amongst GDM mothers was much higher, it was not seen to have a statistical association in our study. However this increased frequency of congenital anomalies in infants of GDM mothers is in concordance with studies conducted by many other researchers ${ }^{15}$.

Male infants had a significantly $(p=0.001)$ higher frequency of anomalies in our study, the rate of $9.3 \%$ was over twice that seen in female neonates (4.3\%). Looking to literature there are several studies ${ }^{9,10}$ that show no statistically significant gender predilection, whereas several other large studies that concur with our findings ${ }^{20,21}$.

Our study revealed no significant association between gestational age and congenital anomalies; however it is an established fact that pregnancies complicated by congenital malformations are at an increased risk of preterm birth ${ }^{22,23}$. The rate of anomalies among infants born in the low and normal birth weight groups was $9.0 \%$ and $6.1 \%$ respectively, compared to the notably higher rate of $16.2 \%$ seen in infants with high birth weight, statistical tests showed a significant $(P=0.005)$ association between birth weight and birth defects. This association can be explained in terms of the conditions that predispose an infant to be born with a high birth weight. Large for Gestation Age and Macrosomic infants are regularly seen in multiparous women or those with GDM; and these maternal variables have a proven association with increased rates of congenital anomalies ${ }^{15}$. There are also several well recognized types of congenital anomalies that are seen in infants with high birth weight: genetic syndromes such as Beckwith Wiedemann and Perlman syndromes, hip subluxation, talipes, brachial plexus injuries ${ }^{24}$, certain cardiac and CNS defects and omphalocele ${ }^{25}$.

The rate of anomalies amongst consanguineous couples was found to be over four-fold more (33.3\%) as compared to the rate of $6.8 \%$ among nonconsanguineous couples in our study, however as there were only 3 infants from consanguineous marriages $(0.2 \%)$ in our study population, the data was insufficient to draw a statistical conclusion. However with rates of consanguineous marriage in the Arab world ranging from $20-57 \%(50 \% \text { among UAE nationals })^{8}$, there is a higher burden of disease due to chromosomal disorders in the region, and several studies have proven a strong statistical association between the rate of congenital anomalies and consanguinity ${ }^{8,13}$.

\section{Conclusion}

The frequency of congenital anomalies from December 2007 - June 2008 was 84 cases out of the total 1,222 live births recorded, the proportion of anomalous births being $6.9 \%$ or 68.7 per 1000 live births. The most common congenital anomalies were of the genitourinary, musculoskeletal and cardiovascular systems. Congenital hydrocele was the most common anomaly followed by talipes and undescended testis. Even though maternal variables like increasing parity, reactive VDRL, positive HBV and Gestational Diabetes Mellitus showed a higher frequency of infants born with a congenital anomaly, none were statistically significant. Infant variables that showed statistically significant association with congenital anomaly were male gender $(p=0.001)$ and high birth-weight $(\geq 4.0 \mathrm{~kg})$ infants $(p=0.005)$.

Acknowledgements: The authors thank the staff at the GMCHRC Records Department, without their support the data collection for this study would not have been possible.

\section{Funding: None \\ Conflict of Interest: None \\ Permission from IRB: Yes}

\section{References}

1. Mosby Mosby's medical dictionary, 6th ed. St. Louis, MO: Elsevier Health Sciences; 2009.

2. EUROCAT [Online]. Special Report: A Review of Environmental Risk Factors for Congenital Anomalies, 2004 [cited 2009 September 15]. Available at: http://www.eurocat-network.eu/ content/Special-Report-Env-Risk-I-and-II.pdf (Accesed $6^{\text {th }}$ January 2012) 
3. Howson $\mathrm{CP}$, Christianson A, Modell B. Controlling Birth Defects: Reducing the Hidden Toll of Dying and Disabled Children in Low-Income Countries. Disease Control Priorities Project [Online]. 2008 [cited 2010 Jan 15]. Available from: http://www. dcp2.org/file/230/dcpp-twpcongenitaldefects_ web.pdf (Accesed $12^{\text {th }}$ January 2012).

4. March of Dimes Birth Defects Foundation [Online]. Global Report on Birth Defects. The Hidden Toll of Dying and Disabled Children. 2006 [cited 2008 September 18]. Available at: http://www. neonatology.org/pdf/MODBDExecutiveSummary. pdf (Accesed 12 ${ }^{\text {th }}$ January 2012).

5. Hosani $H$, National congenital abnormalities registry in UAE (1999-2004). The Ambassadors Online Magazine [Online] 2006; 9 (2) [cited 2010 Jan 15] Available at: http://ambassadors.net/archives/ issue20/selectedstudy8.htm (Accesed $12^{\text {th }}$ January 2012).

6. Hosani HA, Salah M, Abu-Zeid H, Farag HM, Saade D. The National Congenital Anomalies Register in the United Arab Emirates. East Mediterr Health J. 2005; 11(4):690-9.

7. Zain AA, Genetic disorders cost $\$ 200 \mathrm{~m}$ a year. Kaleej Times [Online], 2007 Jan 27. [cited 2010 Jan 15] Available at: http://www.khaleejtimes.com/ktarticle-display-1.asp? section=theuae $\&$ xile=data/ theuae/2007/january/theuae_january932.xml (Accesed 12 $2^{\text {th }}$ January 2012).

8. Aljasir B, Little J, Mandoura NA, AlThani MH. Population health genomics in member countries of the cooperation council for the Arab states of the gulf. Kuwait Med J. 2009; 41(3):187-204.

9. Fida NM, Aama JA, Nichols W, Alqahtani M. A prospective study of congenital malformations among live born neonates at University Hospital in Western Saudi Arabia. Saudi Med J. 2007; 28(9):477483.

10. Karbasi S, Golestan M, Fallah R, Mirnaseri F, Barkhordari K, Bafghee M. Prevalence of Congenital Malformations, Acta Medica Iranica. 2009; 47(2):149-153.

11. Arrayed SS. Epidemiology of congenital abnormalities in Bahrain. East Mediterr Health J 1995; 1(2):248-52.

12. Lissauer T, Clayden G. Illustrated Textbook of Pediatrics, $3^{\text {rd }}$ ed. Spain: Mosby Elsevier; 2007

13. Talabani JA, Shubbar Al, Mustafa KE. Major congenital malformations in United Arab Emirates
(UAE): need for genetic counselling. Ann Hum Genet. 1998; 62: 411-418.

14. Murthy S, Malhotra A, Mani S, Shara M, Al-Rowaished E, AlAli M, et al. Incidence of Down Syndrome in Dubai, UAE. Medical Principles \& Practice. 2007; 16(1):25-28.

15. Refat $M$, Al-Moghanem M, McDonald P, Reyes $L$. Major birth defects at King Fahd Hofuf Hospital: Prevalence, risk factors and outcome. Ann Saudi Med. 1995; 15(4):339-343.

16. Kutcipal RA, Behrman SJ. Maternal blood groups and Complications of pregnancy, Obstetrics \& Gynecology. 1963; 22(5):573-577.

17. Odegard K, Laussen P, Zurakowski D, Hornykewycz S, Laussen J, Hansen D. Distribution of ABO phenotypes in patients with congenital cardiac defects. Cardiology In The Young. 2008; 18(3):307-310.

18. Collmann R, Stoller A. Relation of Congenital Anomalies of the Central Nervous System to the Blood Group of the Mother. Australian \& New Zealand Journal Of Obstetrics \& Gynaecology 1962; 2(1):38-40.

19. Goldenberg RL, Culhane JF, Johnson DC. Maternal infection and adverse fetal and neonatal outcomes. Clin Perinatol. 2005; 32(3):523-59.

20. Lary J, Paulozzi L. Sex differences in the prevalence of human birth defects: A population-based study. Teratology. 2001; 64(5):237-251.

21. Shaw G, Carmichael S, Kaidarova Z, Harris J. Differential risks to males and females for congenital malformations among 2.5 million California births, 1989-1997. Birth Defects Research Part A. Clinical And Molecular Teratology. 2003; 67(12): 953-958.

22. Linhart $Y$ et al. Congenital anomalies are an independent risk factor for neonatal morbidity and perinatal mortality in preterm birth. Euro J Obs Gyne. 2000; 90(1):43-49.

23. Purisch S, DeFranco E, Muglia L, Odibo A, Stamilio D. Preterm birth in pregnancies complicated by major congenital malformations: a population-based study. Amer J Obs Gyne. 2008; 199(3):287-289.

24. Lapunzina P, Camelo JS, Rittler M, Castilla EE. Risks of congenital anomalies in large for gestational age infants. J Pedia. 2002; 140(2):200-204.

25. Waller D, Keddie A, Canfield M, Scheuerle A. Do infants with major congenital anomalies have an excess of macrosomia? Teratology. 2001; 64(6):311-317.

\section{How to cite this article?}

Aryasinghe L, Moezzi D, Ansari TA, Khoury R, Mathew E, Sharbatti SA, Shaikh RB. Congenital Anomalies at Birth: A Hospital Based Study in UAE. J Nepal Paediatr Soc 2012;32(2):105-112. 